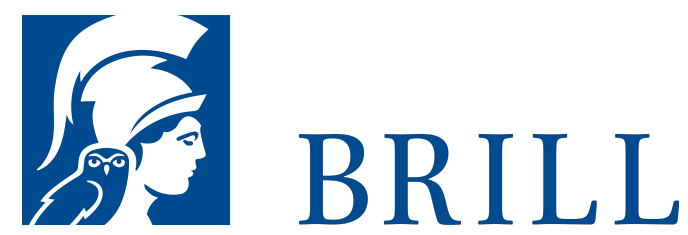

\title{
Die Kantaten von Johann Friedrich Fasch im Licht der pietistischen Frömmigkeit
}

Pietismus und Musik

Author: Elena Sawtschenko

Im Leben des Zerbster Hofkapellmeisters Johann Friedrich Fasch (1688-1758) kreuzen sich Kontakte zu den unterschiedlichsten Strömungen des Pietismus: vom radikalen Pietismus J. W. Petersens bis zur Hallenser Prägung A. H. Franckes; zur Herrnhuter Richtung N. L. Reichsgraf von Zinzendorfs und zu den reisenden Missionaren des ersten protestantischen Insti-tuts zur Judenmission. Am Beispiel von Faschs Kantatenjahrgang Das in Bitte, Gebeth, Fürbitte und Dancksagung bestehende Opffer von 1735/36 wird eine spezielle Frage an die Kantate, der wichtigsten kirchenmusikalischen Gattung in den lutherischen Gebieten Deutschlands, gestellt: ob und wie sich in ihr Momente pietistischer Frömmigkeit erkennen lassen, ob es musikalische Merkmale gibt, die auf eine pietistische Haltung zurückzuführen sind. Der Erhellung des gattungsgeschichtlichen Hintergrunds werden neue Erkenntnisse zur Biographie Faschs vorangestellt (u. a. seine Interpretation eines Zerbster Theologenstreits). Kapitel zu Faschs Auseinandersetzung mit dem Kirchenliedgut im genannten Kan-ta-tenjahrgang und zum liturgischen Kontext runden das Buch ab.

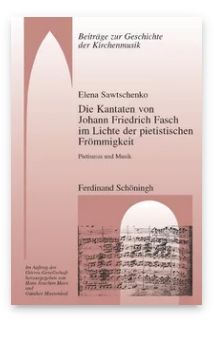

Pages: 344

Seiten

Language:

German

Subjects:

General,

Theology and

World

Christianity

Publisher: Brill |

Schöningh

Series:

Beiträge zur

Geschichte der

Kirchenmusik,

Volume: 14

E-Book (PDF)

Released online:

o3 Feb 2020

ISBN: 978-3-

657-76498-3

List price

USD $\$ 84.00$

Paperback

Publication date:

22 Jul 2009

ISBN: 978-3-

506-76498-о

List price

USD $\$ 84.00$ 
For more information see brill.com

Order information: Order online at brill.com +44330 333 0049 | customerservices@brill.com Submission information: brill.com/authors

Titles published by Brill | Fink, Brill | mentis or Brill | Schöningh: +49(o)715413279216| brill@brocom.de 